\title{
Energy funneling and macromolecular conformational dynamics: a 2D Raman correlation study of PEG melting
}

\author{
Ashok Zachariah Samuel and Siva Umapathy \\ Cascading energy landscapes through funneling has been postulated as a mechanistic route for achieving the lowest energy \\ configuration of a macromolecular system (such as proteins and polymers). In particular, understanding the molecular \\ mechanism for the melting and crystallization of polymers is a challenging fundamental question. The structural modifications \\ that lead to the melting of poly(ethylene glycol) (PEG) are investigated here. Specific Raman bands corresponding to different \\ configurations of the PEG chain have been identified, and the molecular structural dynamics of PEG melting have been \\ addressed using a combination of Raman spectroscopy, 2D Raman correlation and density functional theory (DFT) calculations. \\ The melting dynamics of PEG have been unambiguously explained along the $\mathrm{C}-0$ bond rotation coordinate. \\ Polymer Journal (2014) 46, 330-336; doi:10.1038/pj.2014.10; published online 19 March 2014
}

Keywords: gauche effect; melting dynamics; polyethylene glycol; Raman spectroscopy; two-dimensional correlation

\section{INTRODUCTION}

The polymer crystallization process $^{1}$ and the protein-folding processes $^{2}$ are usually hypothesized as individual segments moving down the free energy landscape through a sequence of conformational reorganizations into an ordered lamellar crystalline state or a functionally folded state. ${ }^{3}$ Understanding these stepwise conformational bond-specific dynamics during the ordering of flexible polymers into lamellar crystalline domains is a challenging fundamental question because of the multi-dimensional conformational space and the complexity associated with the size of the macromolecule. ${ }^{4}$ Previous studies have examined different aspects of polymer crystallization ${ }^{5,6}$ using experimental and theoretical approaches, for example, on poly(ethylene glycol) (PEG) because PEG is an industrial polymer with applications ranging from biology to materials science, such as tribology, liposomes, drug delivery nano-carriers and solid-state batteries. ${ }^{-10}$ The structural dynamics of PEG during crystallization have also been investigated using time-resolved small-angle $\mathrm{X}$-ray scattering measurements, ${ }^{11}$ four-dimensional electron microscopy techniques, ${ }^{12}$ conformation correlation analysis ${ }^{13}$ and molecular dynamics simulations. ${ }^{14}$ However, the molecular bond-specific structural details of the induced conformations (conformational modifications during heating) remain unclear. ${ }^{15-17}$ Considering the wealth of information generally available in the Raman spectrum of PEG ${ }^{18-20}$ we address the specific question of the mechanism of molecular structural dynamics during PEG melting using two-dimensional Raman correlation spectroscopy. ${ }^{21-23}$ The successive structural changes in the system owing to an external perturbation can effectively be explored by employing the two-dimensional correlation methodology. ${ }^{21}$ Such two-dimensional correlation analyses effectively deconvolute overlapping spectral features as well as the sequence of the frequency-specific spectral intensity variations (dynamical information). ${ }^{22,23}$

In the solid state, PEG has been reported to exist predominantly in a helical configuration $\left(7_{2}\right.$ helix) with $\mathrm{O}-\mathrm{C}-\mathrm{C}-\mathrm{O}$ repeat units of the polymer in a trans-gauche-trans (TGT) conformation. ${ }^{24}$ There are three ways in which the PEG helix can change during heating (Scheme 1): the first is where $\mathrm{C}-\mathrm{O}$ single bonds rotate, the second is where $\mathrm{C}-\mathrm{C}$ bonds rotate and the third is where both the bonds rotate. Note that the energetics of these events may differ. However, the structural conformation modifications induced during the melting of PEG remain unclear. For instance, a nuclear magnetic resonance spectroscopic study of molten PEG indicated that the gauche $\mathrm{C}-\mathrm{C}$ conformation is more stable than the trans form, ${ }^{25}$ whereas several other studies have argued that the $\mathrm{O}-\mathrm{C}-\mathrm{C}-\mathrm{O}$ dihedral angle changed from the gauche to trans conformations. ${ }^{3,17}$ Furthermore, the Raman spectral features assigned to the trans $\mathrm{C}-\mathrm{C}$ conformation in the molten state ${ }^{13,26}$ contradict the well-known gauche effect in ethylene glycol, which may also be expected in the polymeric analog. ${ }^{14}$ Thus, in this letter, we have revisited the PEG melting process using Raman spectroscopy and density functional theory (DFT) calculations to understand the configurational cascading of PEG in the free energy landscape. 

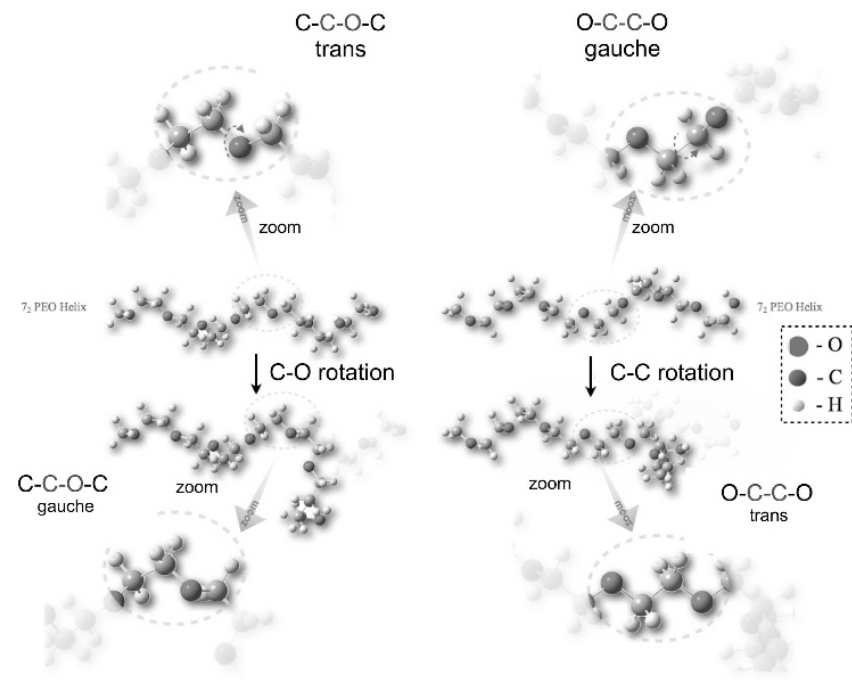

Scheme $1 \mathrm{~A}$ pictorial representation of two possible mechanisms for modification of the PEG helix during melting. The $\mathrm{C}-\mathrm{C}$ and/or $\mathrm{C}-\mathrm{O}$ bond rotation results in the destruction of the helical configuration during melting. A full color version of this scheme is available at Polymer Journal online.

\section{EXPERIMENTAL PROCEDURE}

The PEG used in this study is a polyethylene glycol monomethylether with an average molecular weight of $1000 \mathrm{~g} \mathrm{~mol}^{-1}$ (Sigma-Aldrich, St Louis, MO, USA). The polymer sample was first dissolved in tetrahydrofuran and filtered. Tetrahydrofuran was then removed by evaporation. The polymer was further dried at $100^{\circ} \mathrm{C}$ under vacuum for $3 \mathrm{~h}$ before the experiment. Before the measurement, the sample was subjected to thermal cycling in a heating/cooling stage (from 0 to $70{ }^{\circ} \mathrm{C}$ and back at a rate of $2{ }^{\circ} \mathrm{C} \mathrm{min}-1$ ) to prepare a proper crystalline phase. The Raman spectral data were recorded using a Raman microscope (RM1000, Renishaw, Wotton-under-Edge, UK) equipped with a heating-cooling stage (THMS600, Linkam, Guildford, UK). All the spectra were recorded using a $514.5 \mathrm{~nm}$ argon ion laser (Spectra-Physics, Santa Clara, CA, USA) at a $40 \mathrm{~mW}$ laser power (laser output power) and at a $\times 50$ microscope objective. The PEG sample used for the analysis was equilibrated for $3 \mathrm{~min}$ at each temperature before recording the spectrum. 2-dimensional correlation analysis (Supplementary Information S1) was performed using 2Dshige (Shigeaki Morita, Kwansei-Gakuin University, 2004-2005) software. Gaussian calculations were performed using Gaussian 09 software (Gaussian Inc., Wallingford, CT, USA). ${ }^{27}$ Geometry optimization and frequency calculations were performed using the DFT/B3LYP/6-31 + G(d, p) method available in Gaussian 09. The X-ray crystal structure reported by Takahashi and Tadokora ${ }^{24}$ was used as the model for the helical conformation of PEG. The polymer structure was terminated after seven repeat units, and one of the end groups $(\mathrm{OH})$ was modified as $\mathrm{O}-\mathrm{CH}_{3}$ for calculations. The differential scanning calorimetry (DSC) experiment was performed using a Mettler-Toledo DSC1 (Mettler-Toledo Inc., Columbus, OH, USA) with a heating and cooling rate of $10{ }^{\circ} \mathrm{Cmin}^{-1}$. All of the calculated frequencies presented here are scaled with a uniform scaling factor of 0.985 . The polarized optical microscopy studies were conducted using an Olympus BX-51 microscope (Olympus, Center Valley, PA, USA).

\section{RESULTS AND DISCUSSION}

The Raman spectrum of the solid $\mathrm{PEG}^{19}$ obtained at $20{ }^{\circ} \mathrm{C}$ and the DFT-computed Raman spectrum (using a heptamer model; see Supplementary Information, Supplementary Figure S1) agree well with the helical TGT (about the $\mathrm{O}-\mathrm{C}-\mathrm{C}-\mathrm{O}$ segments of PEG) configuration of PEG. The heptamer PEG model $\left(\mathrm{CH}_{3} \mathrm{O}\left(\mathrm{CH}_{2}\right.\right.$ $\left.\left.\mathrm{CH}_{2} \mathrm{O}\right)_{6} \mathrm{CH}_{3}\right)$ represents one helical repeat unit $\left(7_{2} \text { helix }\right)^{24}$ of the crystalline phase and therefore used to calculate the vibrational frequencies of the helical configuration. A good agreement was observed between the experimental and calculated spectra when compared with other model structures employed previously ${ }^{18,20}$ (Supplementary Information, Supplementary Figure S2). The band assignments and the results of potential energy distribution calculations are provided in the Supplementary Information (Supplementary Table S1). The potential energy distribution results indicate that the 844 and $863 \mathrm{~cm}^{-1}$ modes have a mixed character of $\mathrm{CH}_{2}$-rocking and backbone (C-O and C-C) stretching vibrations. Similarly, the Raman bands from 1450 to $1500 \mathrm{~cm}^{-1}$ have a $\delta(\mathrm{O}-\mathrm{C}-\mathrm{C})+\delta \mathrm{CH}_{2}$-scissoring character (see Supplementary Information, Supplementary Table S1). Therefore, the vibrations associated with $\mathrm{CH}_{2}$-bending are expected to show characteristic changes in response to modifications of the specific bond dihedral angle (backbone) during melting.

To follow the melting process, Raman spectra of PEG (molecular weight $1000 \mathrm{~g} \mathrm{~mol}^{-1}$ ) at different temperatures were recorded over the temperature range $0-70{ }^{\circ} \mathrm{C}$ at an interval of $2{ }^{\circ} \mathrm{C}$. Completely reversible spectral changes were observed within the temperature window of 20 to $40^{\circ} \mathrm{C}$ (Figure 1a). No spectral changes were observed after $40^{\circ} \mathrm{C}$. The DSC thermogram of PEG (polyethylene glycol monomethylether, molecular weight $1000 \mathrm{~g} \mathrm{~mol}^{-1}$ ) and the intensity variation of the $844 \mathrm{~cm}^{-1}$ Raman band (heating and cooling) are shown in Figure 1b. The Raman intensity variations observed during the heating and cooling cycles are similar to the variation observed in the DSC. To discern other Raman spectral differences, we subtracted the Raman spectrum recorded at $20^{\circ} \mathrm{C}$ from all of the other Raman spectra recorded at various temperatures, and the resultant spectra are shown in Figure 1c. In the difference spectra, peaks that decrease in intensity during heating appear with negative intensities, whereas new peaks appear with positive intensities. As expected, the region between 770 and $1130 \mathrm{~cm}^{-1}$, which is owing to the skeletal fingerprint vibrations, shows interesting spectral changes, but the new spectral features that appeared were unusually broad. The peaks at 844 and $863 \mathrm{~cm}^{-1}$ were found to decrease in intensity, whereas the intensities of the 810 and $884 \mathrm{~cm}^{-1}$ peaks increased. The Raman bands in the region between 1130 and $1500 \mathrm{~cm}^{-1}$ show a large decrease in intensity along with an associated broadening during melting. Similarly, changes were also observed in the C-H-stretching region (Figure 1d). In the following sections, we analyze these two regions $\left(800-1500\right.$ and $\left.2750-3100 \mathrm{~cm}^{-1}\right)$ in detail to unravel the molecular mechanism of PEG melting.

\section{C-H-stretching region $\left(2750-3100 \mathrm{~cm}^{-1}\right)$}

Two strikingly different trends of intensity changes were observed in the $\mathrm{C}-\mathrm{H}$-stretching region (Figure 2c). The Raman band at $2940 \mathrm{~cm}^{-1}$ remains stagnant until $30^{\circ} \mathrm{C}$, after which a sharp increase in intensity was observed; whereas, the peak at $2887 \mathrm{~cm}^{-1}$ was found to shift to $2874 \mathrm{~cm}^{-1}$. It is possible that these two peaks are sensitive to completely different processes during the melting of PEG. Unlike the crystallization of small molecules, polymer crystallization is a complex phenomenon. During crystallization, polymer chains fold into lamellar crystallites (secondary structure), and these crystallites organize into three dimensions to form tertiary (or quaternary structure) structures called spherulites. ${ }^{28}$ Polarized optical microscopy-imaging experiments were performed at different temperatures to probe the reason for different responses of the two Raman bands to temperature variations. A birefringent pattern (see Supplementary Information, Supplementary Figure S3) indicative of ordered crystalline lamellae (spherulite) ${ }^{29}$ was observed, and the pattern started to appear diffuse after $30^{\circ} \mathrm{C}$, signifying that the vibrational modes at 2887 and $2940 \mathrm{~cm}^{-1}$ are sensitive to lateral 


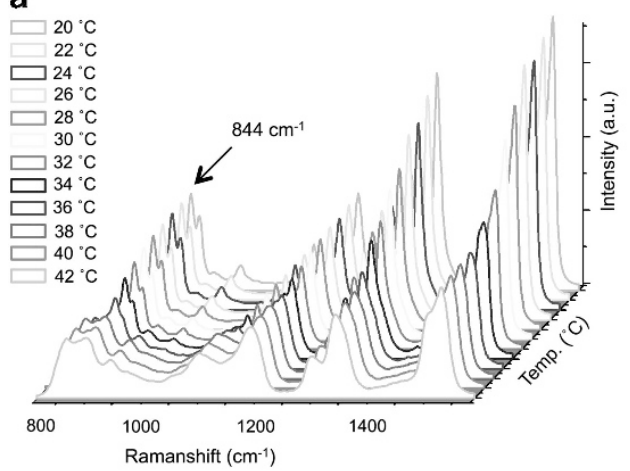

C

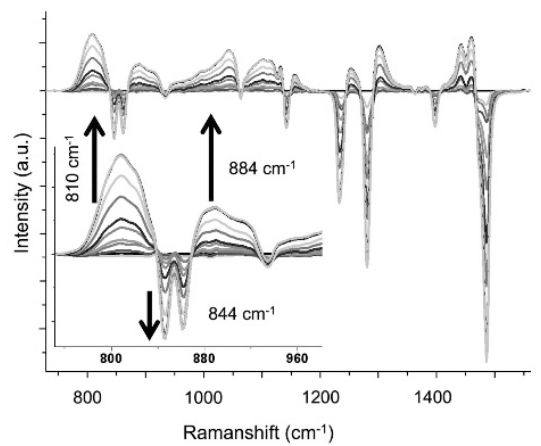

b

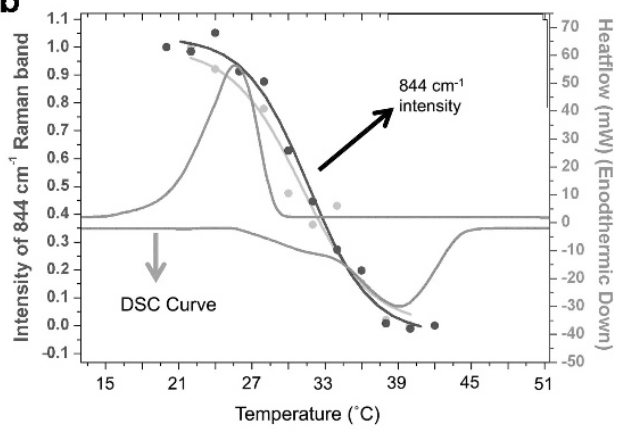

d

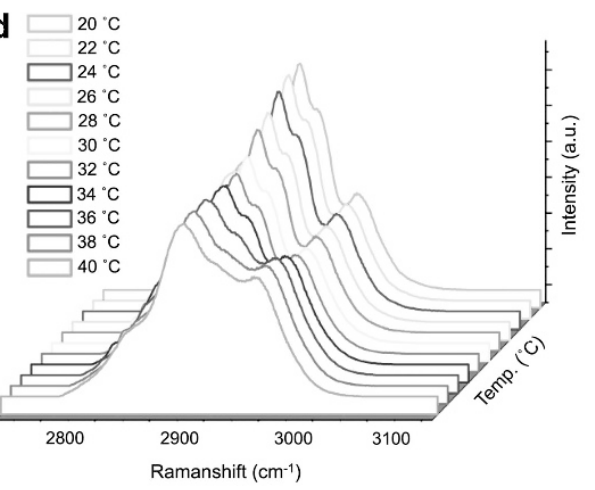

Figure 1 (a) Raman spectra of poly(ethylene glycol) (PEG) (molecular weight 1000) at different temperatures from 20 to $42^{\circ} \mathrm{C}$ (interval of $2{ }^{\circ} \mathrm{C}$ ). (b) differential scanning calorimetry thermogram of PEG (green) together with the intensity variations in the $844 \mathrm{~cm}^{-1}$ Raman band during heating (blue) and during cooling (red). (c) Temperature dependent variation in the difference spectrum. (d) $\mathrm{C}-\mathrm{H}$-stretching region of the Raman spectrum of PEG at different temperatures. A full color version of this figure is available at Polymer Journal online.

(spherulite) ordering of the polymer chains (Figure 2d). Earlier studies on alkanes have demonstrated that the symmetric methylene $\mathrm{C}-\mathrm{H}$-stretching mode $(\mathrm{S}-\mathrm{CH})$ and the asymmetric $\mathrm{C}-\mathrm{H}$-stretching of $\mathrm{CH}_{3}($ As- $\mathrm{CH})$ are sensitive to conformational disorder and the lateral ordering of chains. ${ }^{30}$ Moreover, the ratio of intensity $I_{(\mathrm{As}-\mathrm{CH}) /(\mathrm{S}-\mathrm{CH})}$ has been demonstrated to be sensitive to the conformational changes in alkane chains ${ }^{31}$ and has been widely used to study phase transitions in lipid bilayers and intercalated surfactants. ${ }^{32} \mathrm{~A}$ ratio of $\sim 0.88$, in the case of intercalated surfactant species, ${ }^{33}$ was assigned to the disordered organization of the chains with greater gauche defects. On the basis of our present observations and earlier literature on alkanes, we assign $2887 \mathrm{~cm}^{-1}$ as the symmetric C-H-stretching (S-CH), $2903 \mathrm{~cm}^{-1}$ as the antisymmetric C-H-stretching (Ant-CH) and $2940 \mathrm{~cm}^{-1}$ as the asymmetric $\mathrm{C}-\mathrm{H}$-stretching vibrations of the terminal $\mathrm{CH}_{3}$ (As-CH). ${ }^{31,34}$ In the present case, the intensity ratio of the antisymmetric $\mathrm{C}-\mathrm{H}$-stretching and the symmetric $\mathrm{C}-\mathrm{H}$-stretching ( $I_{2903 / 2887}$ in crystalline PEG and $I_{2903 / 2874}$ in molten PEG) remained the same (0.79 and 0.77) before and after melting. The consistent intensity ratio $\left(I_{(A s-C H) /(S-C H)}\right)$ suggests an unaltered $\mathrm{C}-\mathrm{C}$ gauche conformation along the polymer chain during and after melting. Similarly, in earlier studies the intensity ratio $I_{2887 / 2940}$ was found to be sensitive to the intermolecular interactions. ${ }^{31,32}$ The intensity ratio $I_{2887 / 2940}$ was found to decrease from 2.34 to 1.44 during melting, suggesting a reduced intermolecular interaction compared with the crystalline state. On the basis of the results described above, we propose that the true melting of crystallites begins only after $30^{\circ} \mathrm{C}$, while the changes observed in the Raman spectrum before $30^{\circ} \mathrm{C}$ are owing to the pre-melting dynamics of the polymer chain, in which some of the segments change their conformation from TGT (about
$\mathrm{O}-\mathrm{C}-\mathrm{C}-\mathrm{O})$ to a new higher energy form. During the transformation, the $\mathrm{C}-\mathrm{C}$ dihedral angle most likely remains unchanged.

\section{$800-1500 \mathrm{~cm}^{-1}$ region and computational studies}

As mentioned earlier, prominent changes were also observed in the methylene-rocking region $\left(\sim 800 \mathrm{~cm}^{-1}\right)$, but the features were unusually broad. A plot of the intensity variation of different Raman bands as a function of temperature (response of the system to heating) is given in Figure 2a. Different vibrational modes responded differently to the thermal perturbation. As mentioned earlier, the Raman band at $844 \mathrm{~cm}^{-1}$ is specific to the TGT (helical) configuration along the polymer chain. The intensity of this Raman band decreased during heating, indicating a modification of the helical (TGT) configuration. Consequently, a new band appeared near $810 \mathrm{~cm}^{-1}$, which increased in intensity during melting. Moreover, the scaled intensity modulation at 844 and $810 \mathrm{~cm}^{-1}$ (Figure 2b; see also Supplementary Information S2) suggested a correlation between the existing conformation and the new conformation. Hence, it could be inferred that every new conformation that is thermally induced in the polymer chain $\left(810 \mathrm{~cm}^{-1}\right)$ is a result of a modification of an equivalent number of TGT helical conformations that exist in the solid state $\left(844 \mathrm{~cm}^{-1}\right)$. To explain the new spectral bands that appeared in the methylene-rocking region and to gain more insight into the new conformations formed during melting, we performed DFT calculations using model conformers. The dihedral angles of the heptamer helix (TGT; see Scheme 1) model were modified to generate a new set of conformers that are most likely in the molten state. Three sets of model structures were considered. Details of the model structures studied are provided in the Supplementary Information 

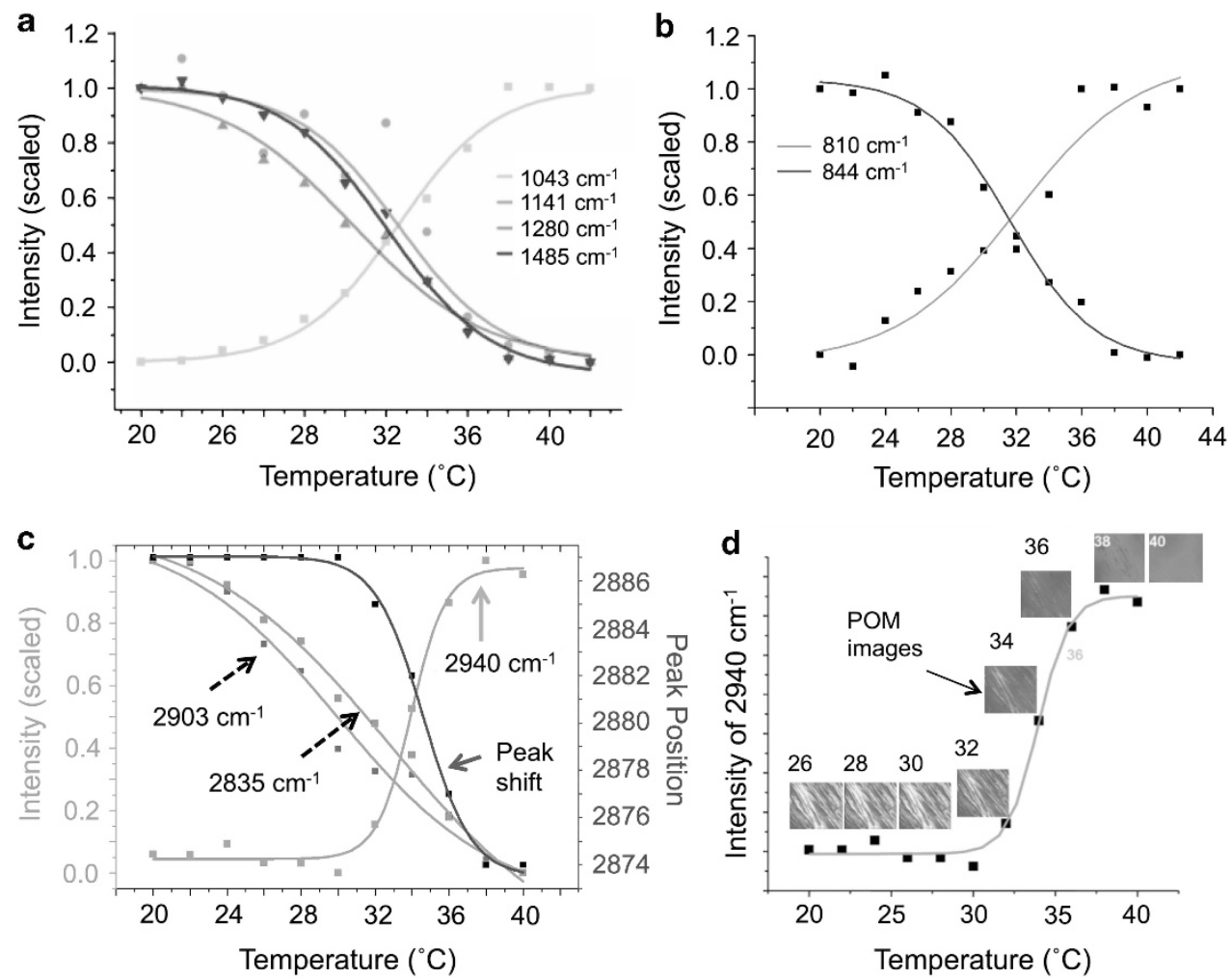

Figure 2 (a) Intensity variations of different Raman bands as a function of temperature. (b) Intensity variations at two different wavenumbers: 810 (new conformer) and $844 \mathrm{~cm}^{-1}$ (helical conformer). (c) Intensity variations at different wavenumbers in the C-H-stretching region. (d) Polarized optical microscopy (POM) image at different temperatures with the intensity variation of the $2940 \mathrm{~cm}^{-1}$ band. A full color version of this figure is available at Polymer Journal online.

(Supplementary Table S2). The first set of model structures were generated by changing the $\mathrm{O}-\mathrm{C}-\mathrm{C}-\mathrm{O}$ dihedral angle from $\sim 60^{\circ}$ (trans) to $\sim 180^{\circ}$ (gauche) without altering the $\mathrm{C}-\mathrm{O}-\mathrm{C}-\mathrm{C}$ dihedral angles. In the second set, the $\mathrm{C}-\mathrm{C}-\mathrm{O}-\mathrm{C}$ and $\mathrm{C}-\mathrm{O}-\mathrm{C}-\mathrm{O}$ dihedral angles were changed from trans to gauche while keeping the $\mathrm{O}-\mathrm{C}-\mathrm{C}-$ $\mathrm{O}$ dihedral angle unchanged. In the third set, both of these dihedral angles were altered from that of the native helical (TGT) structure. These conformers were separately optimized before calculating the vibrational frequencies (DFT/B3LYP/6-31+G $(\mathrm{d}, \mathrm{p})$ ).

The Raman spectra calculated from the first set of models exhibited some interesting trends when the number of trans C-C's were increased in the model polymer chain. The $844 \mathrm{~cm}^{-1}$ Raman band was found to decrease in intensity while that of a new band at $881 \mathrm{~cm}^{-1}$ simultaneously increased in intensity (Supplementary Information, Supplementary Figure S4a). Similarly, a new band was also observed in the $1509 \mathrm{~cm}^{-1}$ region of the calculated spectrum, which became prominent as the number of $\mathrm{C}-\mathrm{C}$ trans conformations were increased in the chain. As mentioned earlier, these modes have a mixed methylenerocking and backbone-stretching character. Hence, the configurational changes in the helical PEG chain owing to dihedral angle changes are expected to affect these vibrational modes. Strikingly, these calculated Raman spectra have no vibrational modes near $810 \mathrm{~cm}^{-1}$, which is a prominent feature observed in the Raman spectrum of molten PEG. This result suggests that the $\mathrm{C}-\mathrm{C}$ dihedral angle variation may not be the mechanism of helix destruction during melting. The presence of the $1509 \mathrm{~cm}^{-1}$ band and the absence of the $810 \mathrm{~cm}^{-1}$ band could be considered as Raman signatures of trans $\mathrm{O}-\mathrm{C}-\mathrm{C}-\mathrm{O}$ dihedral angles in PEG. These Raman spectral features were observed in all-trans PEG segments of a triblock amphiphile, which supports our findings. ${ }^{35,36}$ An experimental study on a PEG segment in a triblock architecture using Raman spectroscopy has shown that the 844 and $859 \mathrm{~cm}^{-1}$ bands disappeared and that the 890 and $1497 \mathrm{~cm}^{-1}$ bands appeared when the sample was kept under tension. ${ }^{35}$ These changes in Raman spectra were also assigned to the conformational reorganization of the helical configuration to a planar zigzag configuration. Another Raman spectroscopic investigation on a similar triblock architecture that contained PEG middle segments also demonstrated the presence of a band between 1501 and $1516 \mathrm{~cm}^{-1}$ when PEG adopted an all-trans conformation $^{36}\left(\mathrm{O}-\mathrm{CH}_{2}-\mathrm{CH}_{2}-\mathrm{O}\right.$ in TTT). From the above discussion, it is clear that the $810 \mathrm{~cm}^{-1}$ band is specific to the $\mathrm{C}-\mathrm{O}$ gauche conformation, whereas the band associated with the $\mathrm{C}-\mathrm{C}$ trans conformation is observed in the range from 1497 to $1516 \mathrm{~cm}^{-1}$. Notably, no new spectral bands were observed in this region during the melting of PEG, confirming that the $\mathrm{C}-\mathrm{C}$ gauche dihedral angle remains unchanged during melting.

The Raman spectra calculated using the second set showed features similar to the Raman spectrum recorded from molten PEG (Figure 3a). In the calculated Raman spectrum, there were more gauche $\mathrm{C}-\mathrm{O}$ conformations as indicated by the new vibrational modes appearing at $\sim 810 \mathrm{~cm}^{-1}$, but no frequencies were observed near $1509 \mathrm{~cm}^{-1}$ (Supplementary Information, Supplementary Figure S4b). To reaffirm the results of the calculations, we performed calculations using the third set of model structures, which consisted of both gauche $\mathrm{C}-\mathrm{O}$ and trans $\mathrm{C}-\mathrm{C}$ conformations (irregular incorporations). It could be observed (Supplementary Information S4c) that whenever the C-C trans conformation was incorporated into the model polymer chain, a band at $1509 \mathrm{~cm}^{-1}$ consistently appeared in the calculated spectrum. Hence, the presence of a Raman band in the region of $1497-1516 \mathrm{~cm}^{-1}$ could be 

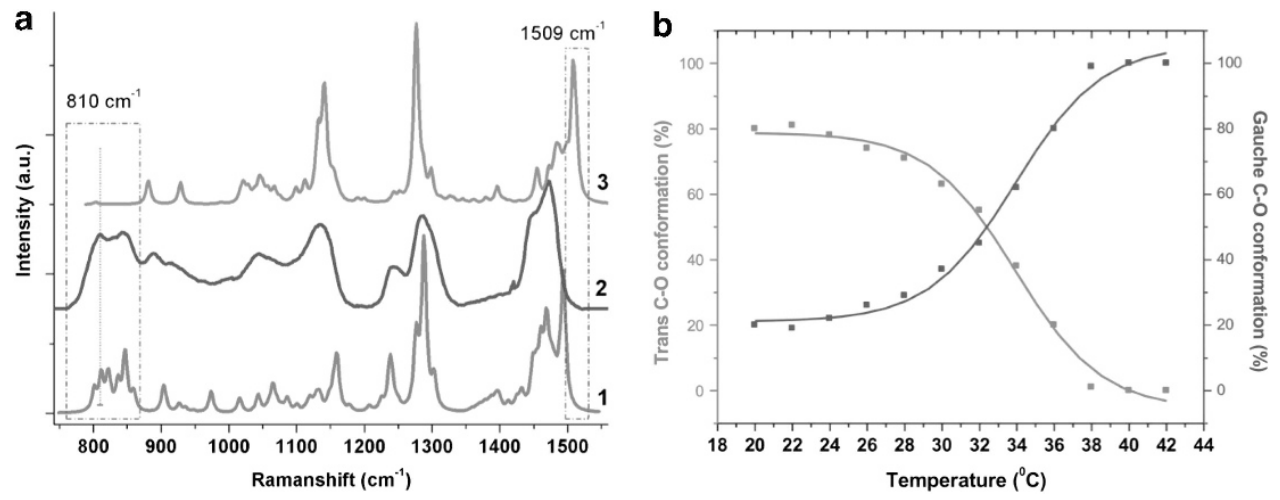

Figure 3 (a) A comparison of the Raman spectrum of molten PEG (2) with the calculated Raman spectrum of a model with a few O-C-C-O in the GGG conformation rather than in the trans-gauche-trans (TGT) conformation (1) and with a few $\mathrm{O}-\mathrm{C}-\mathrm{C}-\mathrm{O}$ in the TTT conformation rather than the TGT conformation (3). The blue spectrum (experimental Raman spectrum of molten PEG) shows a close resemblance to the Raman spectrum of model 1 with $\mathrm{C}-\mathrm{O}$ gauche and $\mathrm{C}-\mathrm{C}$ gauche, suggesting that $\mathrm{C}-\mathrm{O}$ bond rotation preferentially occurs during melting but that the $\mathrm{C}-\mathrm{C}$ remains gauche and does not rotate. The well-known gauche effect in ethylene glycol explains this behavior. (b) The variation of trans and gauche $\mathrm{C}-\mathrm{O}$ conformations in PEG as a function of temperature. A full color version of this figure is available at Polymer Journal online.

considered as a marker band for the $\mathrm{C}-\mathrm{C}$ trans conformations in the PEG chain. The calculated Raman spectrum for two different models (first and second set) and the experimentally obtained Raman spectrum of molten PEG are given in Figure 3a for comparison. It is clear that the calculated spectrum of the model generated through a $\mathrm{C}-\mathrm{O}$ bond rotation (second set) qualitatively explained nearly all the features observed in the Raman spectrum of molten PEG, signifying that during melting, the $\mathrm{C}-\mathrm{O}$ bond rotation preferentially occurs over a $\mathrm{C}-\mathrm{C}$ rotation. We also performed calculations using a tetradecamer helical PEG model (consisting of two $7_{2}$ helical units) and the results were consistent with the explanation given above (Supplementary Information, Supplementary Figure S4d). The new bands in the $810 \mathrm{~cm}^{-1}$ region were hence assigned to the gauche C-O (GGT, TGG and GGG about the $\mathrm{O}-\mathrm{C}-\mathrm{C}-\mathrm{O}$ sequence) sequence in the $\mathrm{PEG}$ chain, consisting of $\mathrm{C}-\mathrm{O}$ and $\mathrm{C}-\mathrm{C}$ gauche conformations along the polymer chain. The results suggested a preference for the gauche $\mathrm{C}-\mathrm{C}$ conformation in the melted polymer (no rotation about the $\mathrm{C}-\mathrm{C}$ single bond during melting). Such a preference for the gauche conformation is generally known as the gauche effect and is well documented for ethylene glycol. ${ }^{37}$ A molecular dynamics simulation study of chain configurations in PEG homolog melts also suggested a similar preference for gauche $\mathrm{C}-\mathrm{C} .{ }^{14}$ Our study clearly demonstrates that the spectral changes observed in the Raman spectrum of PEG during melting is owing to the conformational reorganization of the trans $\mathrm{C}-\mathrm{O}$ conformation to a gauche $\mathrm{C}-\mathrm{O}$ (about the $\mathrm{O}-\mathrm{C}-\mathrm{C}-\mathrm{O}$ sequence) conformation. The trans C-O Raman band $\left(844 \mathrm{~cm}^{-1}\right)$ is characteristic of a crystalline region, and the gauche $\mathrm{C}-\mathrm{O}$ conformation $\left(810 \mathrm{~cm}^{-1}\right)$ represents the amorphous or molten region of PEG. Hence, from the relative band intensities, it is possible to calculate ${ }^{38-40}$ the composition of the trans $\mathrm{C}-\mathrm{O}$ bond, which reflects the percentage crystallinity of the sample. We calculated the percentage of trans $\mathrm{C}-\mathrm{O}$ conformations using the equation given below. The solid PEG at $20^{\circ} \mathrm{C}$ has $81 \pm 1 \%$ trans $\mathrm{C}-$ $\mathrm{O}$ conformation and $19 \pm 1 \%$ gauche $\mathrm{C}-\mathrm{O}$ conformations. These values are in close agreement with the percentage crystallinity of the analogous PEG-1000 determined using DSC. ${ }^{41}$ The plot showing the variations in the content of trans and gauche $\mathrm{C}-\mathrm{O}$ in the polymer as a function of temperature is given in Figure $3 \mathrm{~b}$.

Percentage trans $\mathrm{C}-\mathrm{O}$ in PEG $=100 \frac{I_{\mathrm{T}}}{I_{\mathrm{T}}+I_{\mathrm{G}}\left(\frac{f_{\mathrm{T}}}{f_{\mathrm{G}}}\right)}=100 \frac{A_{844}}{A_{844}+A_{810}\left(\frac{f_{\mathrm{T}}}{f_{\mathrm{G}}}\right)}$ where, $I_{\mathrm{T}}$ and $I_{\mathrm{G}}$ are the intensities of trans and gauche $\mathrm{C}-\mathrm{O}$ bonds, respectively. $f_{\mathrm{T}}$ and $f_{\mathrm{G}}$ are factors that depend on the scattering solid angle, Raman cross-section and the temperature dependent line-shape for trans and gauche $\mathrm{C}-\mathrm{O}$, respectively. $\mathrm{A}_{844}$ and $\mathrm{A}_{810}$ represent the areas under the 844 and $810 \mathrm{~cm}^{-1}$ Raman bands, respectively (For details regarding the derivation and calculation, see Supplementary Information S3).

\section{Segment dynamics of melting PEG}

The two-dimensional Raman correlation spectroscopy methodology was applied to the Raman spectral data set to improve the spectral resolution and to understand the segmental dynamics. The synchronous and asynchronous correlation maps for the Raman spectral region from 770 to $870 \mathrm{~cm}^{-1}$ are shown in Figure 4 (top), and the two-dimensional maps for the other spectral regions are provided in the Supplementary Information (Supplementary Figure S5). Highly resolved spectral information was obtained after the asynchronous correlation analysis. The broad spectral region from 770 to $900 \mathrm{~cm}^{-1}$ was resolved into 13 new bands. A good agreement was observed between the resolved spectral bands obtained from the two-dimensional correlation analysis and the analysis of the second derivative of an average spectrum of the highly overlapped methylene-rocking region (see Supplementary Information, Supplementary Figure S6).

As stated earlier, the fundamental principle that leads to the resolution of broad Raman spectral features in two-dimensional correlation analysis (Figure 4; top) is the difference in the response of different wavenumbers to the external perturbation (temperature). The sequence of spectral intensity modulation during the dynamic events could be retrieved from the asynchronous correlation map. Noda's rules ${ }^{22}$ were applied to find the order in which the vibrational bands modulated during the melting of PEG. The vibration at $934 \mathrm{~cm}^{-1}$, which corresponds to the amorphous domain ${ }^{13,15,17}$ of solid-state PEG, was found to respond to temperature first followed by the bands at $1280,1472,1124$ and $1059 \mathrm{~cm}^{-1}$. The vibrations at 1280,1472 and $1124 \mathrm{~cm}^{-1}$ correspond to the helical polymer chain in the crystalline region (correlates positively with the $844 \mathrm{~cm}^{-1}$ band). Subsequently, the vibration at $1059 \mathrm{~cm}^{-1}$, which is owing to the $\mathrm{C}-\mathrm{O}$ gauche conformer (because it correlates negatively to the $844 \mathrm{~cm}^{-1}$ band), begins to respond. A possible mechanism for the structural modulation could be as follows. As the temperature of the system increases, the $\mathrm{CH}_{2}$-wagging $\left(1280 \mathrm{~cm}^{-1}\right)$ vibration becomes active. 

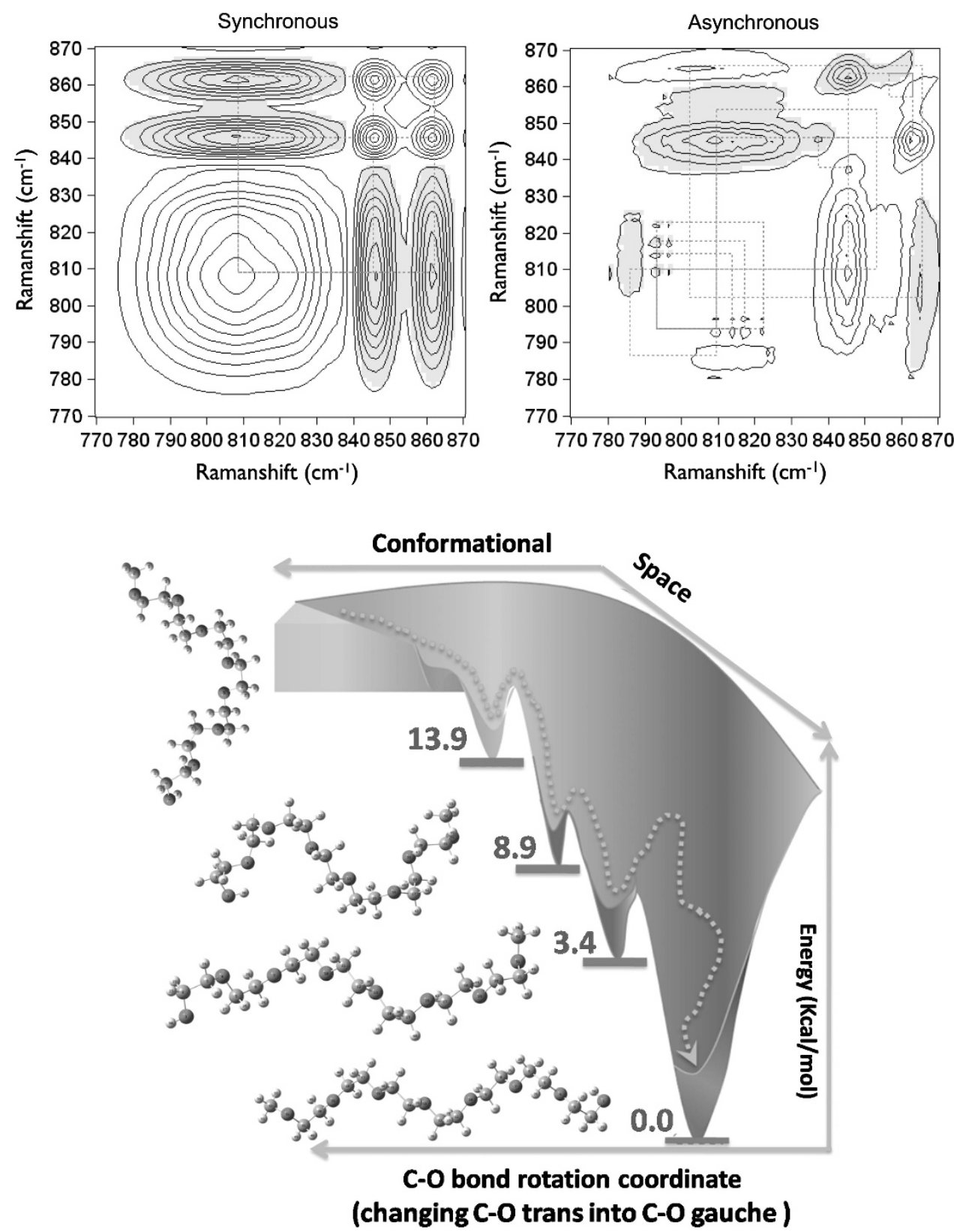

Figure 4 Synchronous and asynchronous two-dimensional correlation plots. (Top; color code: negative correlation as gray and positive correlation as white). A pictorial representation of the single chain dynamics during PEG melting (bottom). A full color version of this figure is available at Polymer Journal online.

Then, the $1472 \mathrm{~cm}^{-1} \mathrm{CH}_{2}$ scissoring vibration, with considerable contribution from a backbone deformation $\left({ }^{\delta} \mathrm{O}-\mathrm{C}-\mathrm{C}+{ }^{\delta} \mathrm{CH}\right)$, becomes active, and this provides flexibility to the chain. Subsequently, the $1124 \mathrm{~cm}^{-1} \mathrm{CH}_{2}$-rocking vibration, with a considerable $\mathrm{C}-\mathrm{O}$-stretching contribution, becomes active and results in the bond rotation. The bond rotation results in the transformation of a few TGT segments to GGG (or GGT or TGG) segments. Consequently, the vibrations of segments containing gauche $\mathrm{C}-\mathrm{O}$ conformations (at $1059 \mathrm{~cm}^{-1}$ ) become active. At higher temperatures, more $\mathrm{C}-\mathrm{O}$ bond rotations occur and eventually result in the melting of the crystalline domain.

The results and discussion to this point clearly demonstrate that the PEG melting process involves stepwise configurational changes in the polymer involving a $\mathrm{C}-\mathrm{O}$ bond rotation. We have also demonstrated that the heptamer helix (TGT) is a good model to represent the PEG polymer chain in the crystalline state (Scheme 1). Hence, the heptamer was modified to construct model conformers that represent the most likely chain configuration in molten PEG. Thus, through computational calculations, we identified the most probable chain configurations in molten PEG. Moreover, the computational studies also indicated minima corresponding to chain configurations of different numbers of $\mathrm{C}-\mathrm{O}$ gauche conformations along the helical (TGT) chain. The energies of these chain configurations were found to increase with the number of $\mathrm{C}-\mathrm{O}$ gauche conformations along the chain. Hence, the number of $\mathrm{C}-\mathrm{O}$ gauche conformations thermally induced in the polymer chain is a function of temperature. Thus, the PEG melting process (and similarly, crystallization, but in the reverse direction) is a cascading process in which the $\mathrm{C}-\mathrm{O}$ bond rotation (trans) in crystalline to gauche in molten state) leads to a higher energy polymer configuration, and this is pictorially illustrated in Figure 4 (bottom). The barrier 
to each configuration is the $\mathrm{C}-\mathrm{O}$ bond rotation barrier; because the energy barrier is dependent on the local environment of the chain in the crystal, it is difficult to measure experimentally. However, it is clear that the molecule has to go through a large number of cascading processes to achieve its lowest energy helical configuration when cooled from an equilibrium temperature close to its melting point. The time required for such a helical reconstruction has been measured in a recent temperature-jump experiment, which supports our findings. ${ }^{12}$

In summary, we have demonstrated that a specific stepwise chain configuration of PEG could be identified using Raman spectroscopy. The two-dimensional Raman correlation spectroscopic study revealed the PEG segment dynamics during melting. The results suggest that the $\mathrm{CH}_{2}$-wagging vibration responds to temperature first, followed by $\mathrm{CH}_{2}$-bending vibrations with considerable backbone $\mathrm{C}-\mathrm{O}$-stretching character. This leads to a $\mathrm{C}-\mathrm{O}$ bond rotation, the destruction of the helical configuration and the eventual melting of PEG. This study unambiguously demonstrates that the molecular mechanism of PEG melting is a $\mathrm{C}-\mathrm{O}$ bond rotation and that the $\mathrm{C}-\mathrm{C}$ dihedral angle remains in a gauche conformation during melting (gauche effect in the PEG melt).

\section{CONFLICT OF INTEREST}

The authors declare no conflict of interest.

\section{ACKNOWLEDGEMENTS}

We thank DST, DRDO and IISc for financial support. We thank S Ramakrishnan for his valuable suggestions and discussions. AZS thanks CSIR for a fellowship. SU acknowledges the JC Bose Fellowship from DST.

1 Dill, K. A. Polymer principles and protein folding. Protein Sci. 8, 1166-1180 (1999).

2 Pande, V. S. \& Rokhsar, D. S. Folding pathway of a lattice model for proteins. Proc. Natl Acad. Sci. USA 96, 1273-1278 (1999).

3 Muthukumar, M. Shifting paradigms in polymer crystallization. Lect. Notes Phys. 714 $1-18$ (2007)

4 Kimata, S., Sakurai, T., Nozue, Y., Kasahara, T., Yamaguchi, N., Karino, T., Shibayama, M. \& Kornfield, J. A. Molecular basis of the shish-kebab morphology in polyme crystallization. Science 316, 1014-1017 (2007).

5 Rastogi, S., Lippits, D. R., Peters, G. W., Graf, R., Yao, Y. \& Spiess, H. W. Heterogeneity in polymer melts from melting of polymer crystals. Nat. Mater. 4, 635-641 (2005).

6 Wang, H., Keum, J. K., Hiltner, A., Baer, E., Freeman, B., Rozanski, A. \& Galeski, A Confined crystallization of polyethylene oxide in nanolayer assemblies. Science 323, 757-760 (2009).

7 Drobek, T. \& Spencer, N. D. Nanotribology of surface-grafted PEG layers in an aqueous environment. Langmuir 24, 1484-1488 (2008).

8 Gabizon, A. A., Tzemach, D., Mak, L., Bronstein, M. \& Horowitz, A. T. Dependency of pharmacokinetics and therapeutic efficacy of pegylated liposomal doxorubicin (DOXIL) in murine models. J. Drug Targeting 10, 539-548 (2002).

9 Onyuksel, H., Ikezaki, H., Patel, M., Gao, X. P. \& Rubinstein, I. A novel formulation of VIP in sterically stabilized micelles amplifies vasodilation in vivo. Pharm. Res. 16 155-160 (1999).

10 Christie, A. M., Lilley, S. J., Staunton, E., Andreev, Y. G. \& Bruce, P. G. Increasing the conductivity of crystalline polymer electrolytes. Nature 433, 50-53 (2005).

11 Lisowski, M. S., Liu, Q., Cho, J. \& Runt, J. Crystallization behavior of poly(ethylene oxide) and its blends using time-resolved wide- and small-angle X-ray scattering. Macromolecules 33, 4842-4849 (2000).

12 Kwon, O. H., Ortalan, V. \& Zewail, A. H. Macromolecular structural dynamics visualized by pulsed dose control in 4D electron microscopy. Proc. Natl Acad. Sci. USA 108, 6026-6031 (2011)

13 Matsuura, H. \& Fukuhara, K. Vibrational spectroscopic studies of conformation of poly(oxyethylene). II. Conformation-spectrum correlations. J. Polym. Sci. Part B. Polym. Phys. 24, 1383-1400 (1986)

14 Neyertz, S. \& Brown, D. A computer simulation study of the chain configurations in poly(ethylene oxide)-homolog melts. J. Chem. Phys. 102, 9725-9736 (1995).

15 Koenig, J. L. \& Angood, A. C. Raman spectra of poly(ethylene glycols) in solution. J. Polym. Sci. 8, 1787-1796 (1970).

16 Connor, T. M. \& McLauchlan, K. A. High resolution nuclear resonance studies of the chain conformation of polyethylene oxide. J. Phys. Chem. 69, 1888-1893 (1965).
17 Matsuura, H. \& Miyazawa, T. Vibraional analysis of molten poly(ethylene glycol) J. Polym. Sci. 7, 1735-1744 (1969).

18 Davison, W. H. T. Infrared spectra and crystallinity. Part III. Poly(ethylene glycol). J. Chem. Soc. 3270-3274 (1955)

19 Kozielski, M., Muhle, M. \& Blaszczak, Z. The Raman scattering study of selected polyoxyethyleneglycols. J. Mol. Liq. 111, 1-5 (2004).

20 Murcko, M. A. \& DiPaola, R. A. Ab initio molecular orbital conformational analysis of prototypical organic systems. 1. Ethylene glycol and 1,2-dimethoxyethane. J. Am. Chem. Soc. 114, 10010-10018 (1992).

21 Noda, I., Dowrey, A. E., Marcoli, C., Story, G. M. \& Ozaki, Y. Generalized twodimensional correlation spectroscopy. Appl. Spectrosc. 54, 236A-248A (2000).

22 Zheng, K., Liu, R. \& Huang, Y. A two-dimensional ir correlation spectroscopic study of the conformational changes in syndiotactic polypropylene during crystallization conformational changes of sPP. Polym. J. 42, 81 (2010).

$23 \mathrm{Wu}$, Y., Meersman, F. \& Ozaki, Y. A novel application of hybrid two-dimensional correlation infrared spectroscopy: exploration of the reversibility of the pressure- and temperature-induced phase separation of poly(n-isopropylacrylamide) and poly(n-isopropylmethacrylamide) in aqueous solution. Macromolecules 39, 1182-1188 (2006).

24 Takahashi, Y. \& Tadokoro, H. Structural studies of polyethers, (-(CH2)m-O-)n. X. crystal structure of poly(ethylene oxide). Macromolecules 6, 672-675 (1973).

25 Connor, T. M. \& McLauchlan, K. A. High resolution nuclear resonance studies of the chain conformation of polyethylene oxide. J. Phys. Chem. 69, 1888-1893 (1965).

26 Barroso-Bujans, F., Fernandez-Alonso, F., Pomposo, J. A., Cerveny, S., Alegría, A. \& Colmenero, J. Macromolecular structure and vibrational dynamics of confined poly(ethylene oxide): from subnanometer $2 \mathrm{~d}$-intercalation into graphite oxide to surface adsorption onto graphene sheets. ACS Macro Lett. 1, 550-554 (2012).

27 Frisch, M. J., Trucks, G. W., Schlegel, H. B., Scuseria, G. E., Robb, M. A., Cheeseman, J. R., Scalmani, G., Barone, V., Mennucci, B., Petersson, G. A., Nakatsuji, H., Caricato, M., Li, X., Hratchian, H. P., Izmaylov, A. F., Bloino, J., Zheng, G., Sonnenberg, J. L., Hada, M., Ehara, M., Toyota, K., Fukuda, R., Hasegawa, J., Ishida, M., Nakajima, T., Honda, Y., Kitao, O., Nakai, H., Vreven, T., Montgomery, J. A. Jr, Peralta, J. E., Ogliaro, F., Bearpark, M., Heyd, J. J., Brothers, E. Kudin, K. N., Staroverov, V. N., Kobayashi, R., Normand, J., Raghavachari, K., Rendell, A., Burant, J. C., Iyengar, S. S., Tomasi, J., Cossi, M., Rega, N., Millam, J. M., Klene, M., Knox, J. E., Cross, J. B., Bakken, V., Adamo, C., Jaramillo, J., Gomperts, R., Stratmann, R. E., Yazyev, O., Austin, A. J., Cammi, R., Pomelli, C. Ochterski, J. W., Martin, R. L., Morokuma, K., Zakrzewski, V. G., Voth, G. A., Salvador, P., Dannenberg, J. J., Dapprich, S., Daniels, A. D., Farkas, Ö., Foresman, J. B., Ortiz, J. V., Cioslowski, J. \& Fox, D. J. Gaussian 09. (Gaussian, Inc., Wallingford CT, 2009).

28 Flory, P. J. On the morphology of the crystalline state in polymers. J. Am. Chem. Soc 84, 2857-2867 (1962).

29 Nozue, Y., Shinohara, Y., Ogawa, Y., Sakurai, T., Hori, H., Kasahara, T., Yamaguchi, N., Yagi, N. \& Amemiya, Y. Deformation behavior of isotactic polypropylene spherulite during hot drawing investigated by simultaneous microbeam SAXS-WAXS and POM measurement. Macromolecules 40, 2036-2045 (2007)

30 Naik, V. V. \& Vasudevan, S. Effect of alkyl chain arrangement on conformation and dynamics in a surfactant intercalated layered double hydroxide: spectroscopic measurements and MD simulations. J. Phys. Chem. C 115, 8221-8232 (2011).

31 Cameron, D. G., Casal, H. L. \& Mantsch, H. H. Characterization of the pretransition in 1,2-dipalmitoyl-sn-glycero-3-phosphocholine by Fourier transform infrared spectroscopy. Biochemistry 19, 3665-3672 (1980).

32 Hill, I. R. \& Levin, I. W. Vibrational spectra and carbon-hydrogen stretching mode assignments for a series of n-alkyl carboxylic acids. J. Chem. Phys. 70, 842-851 (1979)

33 Venkataraman, N. V. \& Vasudevan, S. Conformation of methylene chains in an intercalated surfactant bilayer. J. Phys. Chem. B 105, 1805-1812 (2001)

34 Snyder, R. G., Strauss, H. L. \& Elliger, C. A. Carbon-hydrogen stretching modes and the structure of n-alkyl chains. 1. long, disordered chains. J. Phys. Chem. 86, 5145-5150 (1982)

35 Ding, Y., Rabolt, J. F., Chen, Y., Olson, K. L. \& Baker, G. L. Studies of chain conformation in triblock oligomers and microblock copolymers of ethylene and ethylene oxide. Macromolecule 35, 3914-3920 (2002).

36 Fukuhara, K., Sagawa, T., Kihara, S. \& Matsuura, H. Extended oxyethylene chain in triblock compounds $\alpha$-octyl- $\omega$ octyloxyoligo (oxyethylene)s studied by Raman spectroscopy. J. Mol. Struct. 379, 197-204 (1996).

37 Wolfe, S. Gauche effect. Stereochemical consequences of adjacent electron pairs and polar bonds. Acc. Chem. Res. 5, 102-111 (1972)

38 Gatos, K. G., Minogianni, C. \& Galiotis, C. Quantifying crystalline fraction within polymer spherulites. Macromolecules 40, 786-789 (2007).

39 Kellar, E. J. C., Evans, A. M., Knowles, J., Galiotis, C. \& Andrews, E. H. Raman vibrational studies of syndiotactic polystyrene. 2 . use of the fundamental $v_{1}$ vibrationa mode as a quantitative measure of crystallinity within isotropic material. Macromolecules 30, 2400-2407 (1997).

40 Strobl, G. R. \& Hagedorn, W. Raman spectroscopic method for determining the crystallinity of polyethylene. J. Polym. Sci. Polym. Phys. Ed. 16, 1181-1193 (1978).

41 Pielichowski, K. \& Flejtuch, K. Differential scanning calorimetry studies on poly(ethylene glycol) with different molecular weights for thermal energy storage materials Polym. Adv. technol. 13, 690-696 (2002).

Supplementary Information accompanies the paper on Polymer Journal website (http://www.nature.com/pj) 